\title{
An EQCM study for a novel aromatic poly(amine-imide) electrochromic thin film is
}

\author{
Tsui-Ling Yen ${ }^{\mathrm{a}}$, Hwa-Chiang Lo ${ }^{\mathrm{b}, \mathrm{c}}$, Guey-Sheng Liou ${ }^{\mathrm{d}}$, Kuo-Chuan Ho $\mathrm{Ho}^{\mathrm{a}, \mathrm{b}, *}$ \\ ${ }^{a}$ Institute of Polymer Science and Engineering, National Taiwan University, Taipei 10617, Taiwan \\ ${ }^{\mathrm{b}}$ Department of Chemical Engineering, National Taiwan University, Taipei 10617, Taiwan \\ ${ }^{\mathrm{c}}$ Material and Chemical Research Laboratories, Industrial Technology Research Institute, Chutung, Hsinchu 310, Taiwan \\ ${ }^{\mathrm{d}}$ Department of Applied Chemistry, National Chi Nan University, Puli, Nantou Hsien 545, Taiwan
}

Received 13 February 2007; accepted 2 March 2007

Available online 27 September 2007

\begin{abstract}
A new aromatic poly(amine-imide) electrochromic thin film synthesized with $N, N$-bis(4-aminophenyl)- $N^{\prime}, N^{\prime}$-diphenyl-1,4-phenyle-

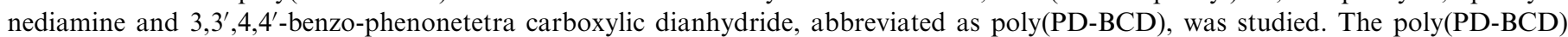
thin-film electrode has been characterized by cyclic voltammetry (CV) and electrochemical quartz crystal microbalance (EQCM). As the polymer chain acquires positive charge during the oxidation of poly(PD-BCD) to its radical cation state or dication state, the anions would insert into the polymer matrix in order to neutralize the charge. However, when the electrodes were cycled in electrolytes

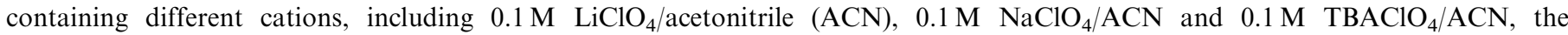
experimental results revealed two mechanisms for the redox reaction. A plot of mass change $(\Delta m)$ vs. accumulated charge $(Q)$ gave a slope, from which the electrochromic mechanism can be extracted. The slopes of $\Delta m-Q$ obtained from the CV-EQCM measurements in three electrolytes were different for the first redox stage, but the slopes were almost the same for the second redox stage. This means that, in addition to the involvement of anions, cations also play an important role in the first redox stage, however, the role of the cations is less in the second stage. Moreover, two reaction mechanisms for the two reaction stages of poly(PD-BCD) are proposed in this study. (C) 2007 Elsevier B.V. All rights reserved.
\end{abstract}

Keywords: EQCM; Ionic transport; PEDOT; Poly(amine-imide); $N, N, N^{\prime}, N^{\prime}$-p-Phenylenediamine derivatives; Redox mechanism

\section{Introduction}

Electrochemical quartz crystal microbalance (EQCM) is a useful apparatus to investigate the mutual relations between a film electrode and the species (such as anions, cations and solvent) contained in the electrolyte solution during the course of electrochemical reactions. With an EQCM instrument, the electropolymerization reaction and redox cycling [1-5] of some conducting polymers (CP) have been studied. For instance, poly(3,4-ethylenedioxythiophene) (PEDOT) is a famous CP that has attracted much

\footnotetext{
This paper has been presented at the 7th International Meeting on Electrochromism (IME-7), Istanbul, Turkey, September 3-7, 2006.

${ }^{*}$ Corresponding author. Institute of Polymer Science and Engineering, National Taiwan University, Taipei 10617, Taiwan.

Tel.: + 886223660739 ; fax: +886223623040 .

E-mail address: kcho@ntu.edu.tw (K.-C. Ho).
}

attention, recently. Bund and Neudeck [6] opined that in a certain potential window (from -0.8 to $0.8 \mathrm{~V}$ vs. $\mathrm{Ag} / \mathrm{AgCl}$ ), both anions and solvent play important role in the mass changes of PEDOT film during the oxidative process, since the exchange of cations was not obvious in the same condition. However, Li et al. [7] proposed that not only anions but also cations would participate in the doping and de-doping processes of PEDOT (from -0.9 to $0.6 \mathrm{~V}$ vs. $\mathrm{Ag} / \mathrm{AgCl})$, in which they also indicated that the exchange of solvent would come about, too, showing less influence on mass change. Even though the point of view toward the same investigative materials may be different, the EQCM technique indeed provides a good method to investigate the reaction mechanism of electroactive materials.

In addition to study the insertion and extraction condition of the ions and solvent, the EQCM technique has also been used in some other research, like biosensors 
[8-10], growth of thin films based on electropolymerized and self-assembled techniques [11-15] and electrodeposition of metals and alloys $[16,17]$.

In this study, a new aromatic poly(amine-imide) electrochromic thin film synthesized with $N, N$-bis(4-aminophenyl)- $N^{\prime}, N^{\prime}$-diphenyl-1,4-phenylenediamine (PD) and 3,3',4,4'-benzo-phenonetetra carboxylic dianhydride (BCD), abbreviated as poly(PD-BCD), was characterized by cyclic voltammetry $(\mathrm{CV})$ and $\mathrm{EQCM}$ in which, the poly(PD-BCD) thin-film electrode exhibited two redox reaction stages during the potential cycling from 0.10 to $0.90 \mathrm{~V}$ (vs. $\mathrm{Ag} / \mathrm{Ag}^{+}$). With the electrolyte containing different cations, the cationic effects toward the poly(PDBCD) film were confirmed. Furthermore, two reaction mechanisms for the two reaction stages of poly(PD-BCD) were proposed in this study.

When poly(PD-BCD) was oxidized to its radical cation and dication states, the film became colored. At the radical cation state, it becomes light green and at the dication state, the color is changed to deep blue. So, poly(PD-BCD) film is a superior candidate for electrochromism. In other areas of research, the derivatives of $N, N$-bis(4-aminophenyl)- $N^{\prime}, N^{\prime}$-diphenyl-1,4-phenylenediamine (PD) had been used in multilayer organic light-emitting diodes [18].

\section{Experimental}

The synthetic procedures of poly(PD-BCD) have been reported [19]. With an appropriate amount of poly(PDBCD) material dissolved in the 1-methyl-2-pyrrolidinone (NMP) (Lancaster, 99.5\%) solvent to make a $0.3 \mathrm{wt} \%$ polymer solution, the polymer solution $(4.5 \mu \mathrm{l})$ was dripped onto the working electrode and the polymer-coated electrode was put into an oven at $60^{\circ} \mathrm{C}$ for $5 \mathrm{~h}$ where the temperatures were increased sequentially to $100,120,150$ and $180^{\circ} \mathrm{C}$ for $2 \mathrm{~h}$ in order to remove the NMP solvent. A vacuum was applied continuously during the evaporative process, for accelerating the evaporation step. Finally, the vacuum was released and the oven temperature was decreased slowly to room temperature.

All of the electrochemical experiments were performed in air at room temperature and controlled by a potentiostat/ galvanostat (Eco-Chemie, Autolab, PGSTAT30). The poly(PD-BCD) thin-film electrode was characterized by a three-electrode electrochemical cell, in which a platinum plate was served as a counter-electrode, a home-made $\mathrm{Ag} / \mathrm{Ag}^{+}$as reference electrode and platinum-coated quartz crystal electrode modified with poly(PD-BCD) as the working electrode. The working electrode possesses an area of $0.196 \mathrm{~cm}^{2}$, and the shear modulus of quartz $(N)$ is $167 \mathrm{kHz} \mathrm{cm}$, density of crystal $\left(r_{\mathrm{q}}\right)$ is $2.648 \mathrm{~g} / \mathrm{cm}^{3}$, resonant frequency of the fundamental mode of the crystal $\left(f_{0}\right)$ is $8.88 \mathrm{MHz}$. With the Sauerbrey equation [20] shown in Eq. (1), the resonant frequency variation obtained from EQCM (EG\&G, model QCA-917) measurements could be transferred into the mass change of this film electrode:

$\Delta f=\left[\frac{f_{0}^{2}}{N \times r_{\mathrm{q}}}\right] \times \Delta m$.

The electrolyte solution used in cyclic voltammetric (CV) analysis comprises of $0.1 \mathrm{M} \mathrm{LiClO}_{4}$ (Aldrich, 95+\%), $0.1 \mathrm{M} \mathrm{NaClO}_{4}$ (Aldrich, 95+\%) and $0.1 \mathrm{M} \mathrm{TBAClO} 4$ (Aldrich, 99\%), respectively, in acetonitrile (ACN) (TEDIA, $99.95 \%$ ), and all of the solutions were dehydrated by 4- $\AA$ molecular sieves from Acros.

\section{Results and discussion}

\subsection{Redox process and the resonance form of poly $(P D-B C D)$}

When poly(PD-BCD) film was oxidized to its oxidative state, the polymer chain would possess positive charge and anions would insert into the polymer matrix in order to neutralize the charge. Fig. 1 shows the simplified redox process and the resonance form of poly(PD-BCD), in which $\mathrm{N} 1$ and $\mathrm{N} 2$ atoms are the two redox reaction centers corresponding to the first and the second stages of electrochemical reactions, respectively. The electronic resonance of phenyl groups near the N2 atom would be affected by the substituent group, 3,3',4,4'-benzophenonetetra carboxylic dianhydride, in which the carboxyl groups of the substituent group are electron withdrawing and this would further influence the electronic configurations of $\mathrm{N} 2$ atom. In other words, the density of electron around N2 atom would be less than that of N1. Upon oxidation, the N1 atom in poly(PD-BCD) would be oxidized first, followed by N2 atom when the applied voltage is increased.

When poly(PD-BCD) film was oxidized to its radical cation state, a succession of resonant reactions would occur. According to the different resonance forms, they have been classified as "path A" and "path B" (see Fig. 1). In path $\mathrm{A}$, the radical of $\mathrm{N} 1$ atom would resonate to the phenyl group near $\mathrm{N} 2$ atom and in the other path the radical would resonate to the phenyl groups near N1 atom. As path A has accomplished, the N2 atom could further be oxidized when a higher voltage was applied and the film would become the dication state. However, the N2 atom does not undergo further oxidation through path $\mathrm{B}$. This means that it is necessary to invoke path A for the second redox reaction of poly(PD-BCD).

When the poly(PD-BCD) film was cycled in the electrolyte solution, not only anions but also cations took part in the reaction, thus, the redox processes of poly(PDBCD) conjectured in Fig. 1 are incomplete. We will have more discussion about this in Sections 3.2.1 and 3.2.2.

\section{2. $C V$ and $E Q C M$ analysis of poly (PD-BCD)}

When poly(PD-BCD) film was cycled in the ACN containing $0.1 \mathrm{M} \mathrm{LiClO}_{4}$, the $\mathrm{CV}$ showed two stages of 
148

T.-L. Yen et al. / Solar Energy Materials \& Solar Cells 92 (2008) 146-153
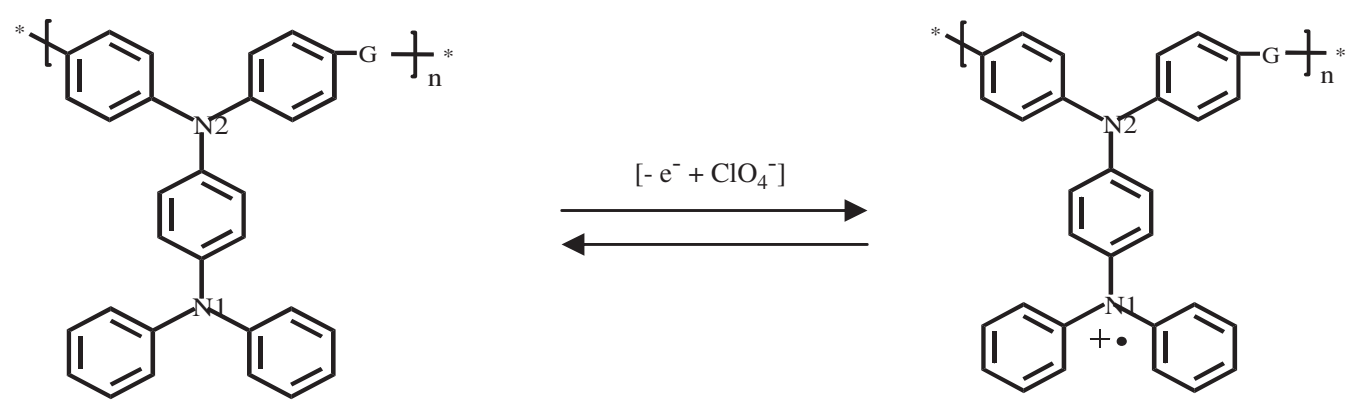

G(substituted group):
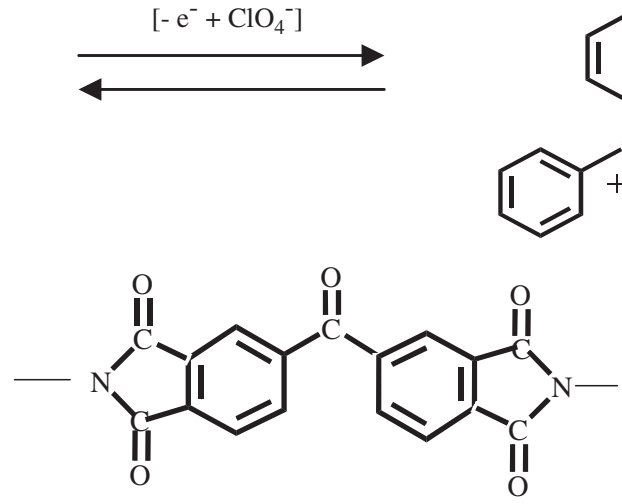

Path A :
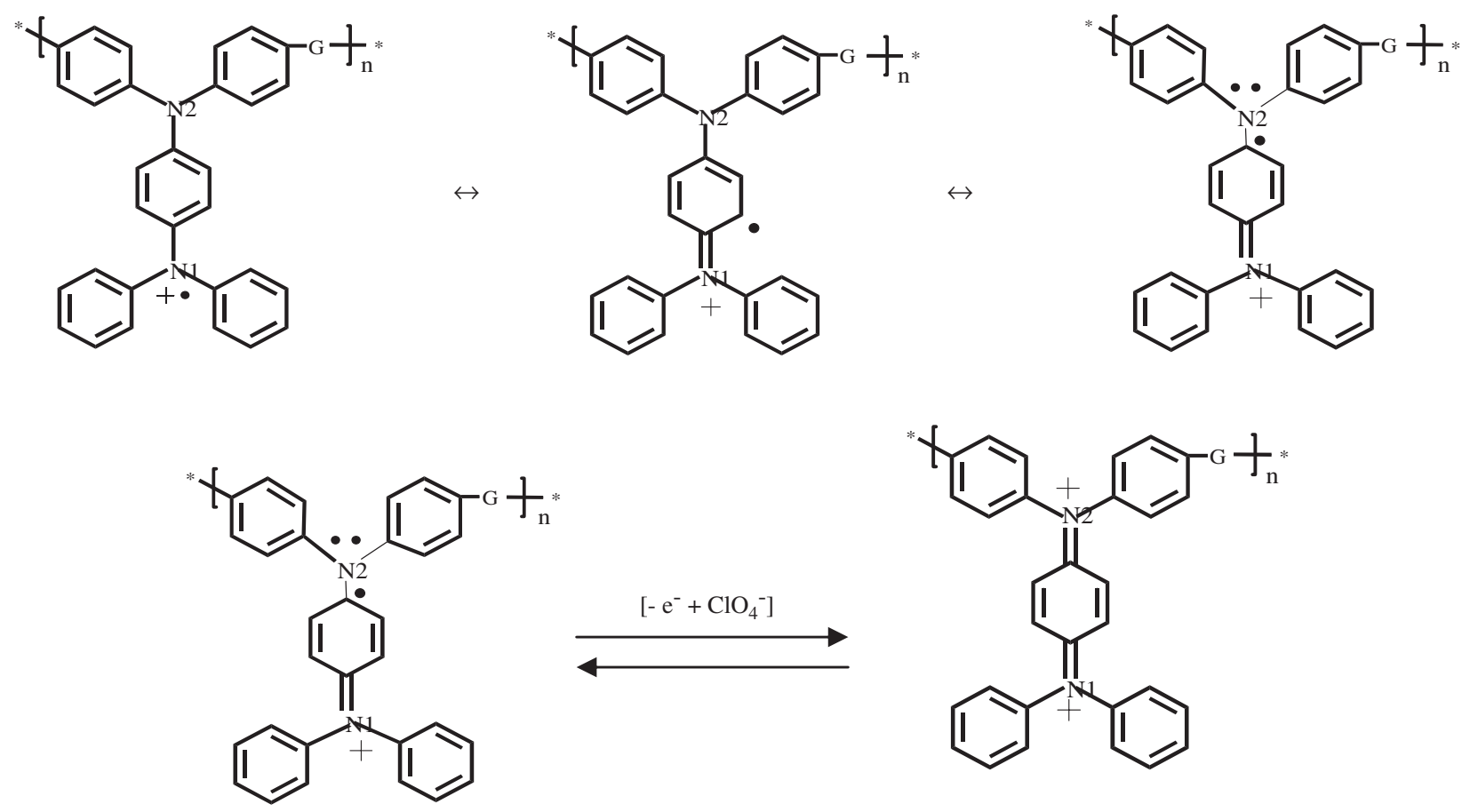

Path B :
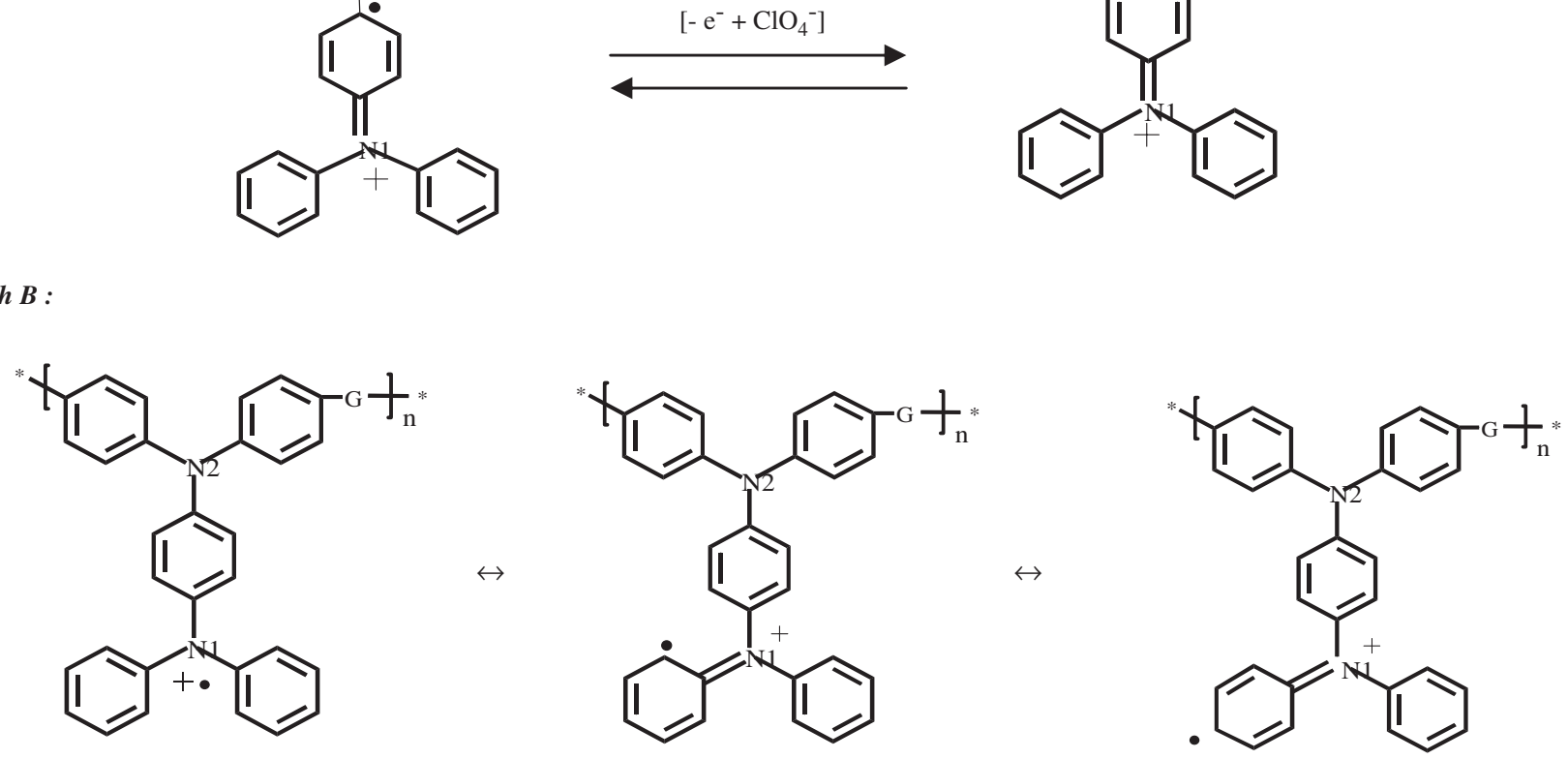

Fig. 1. The simplified redon process of poly(PD-BCD) from its neutral state, radical cation state to diction state. Paths A and B are the two probable paths for the resonance of radical. 


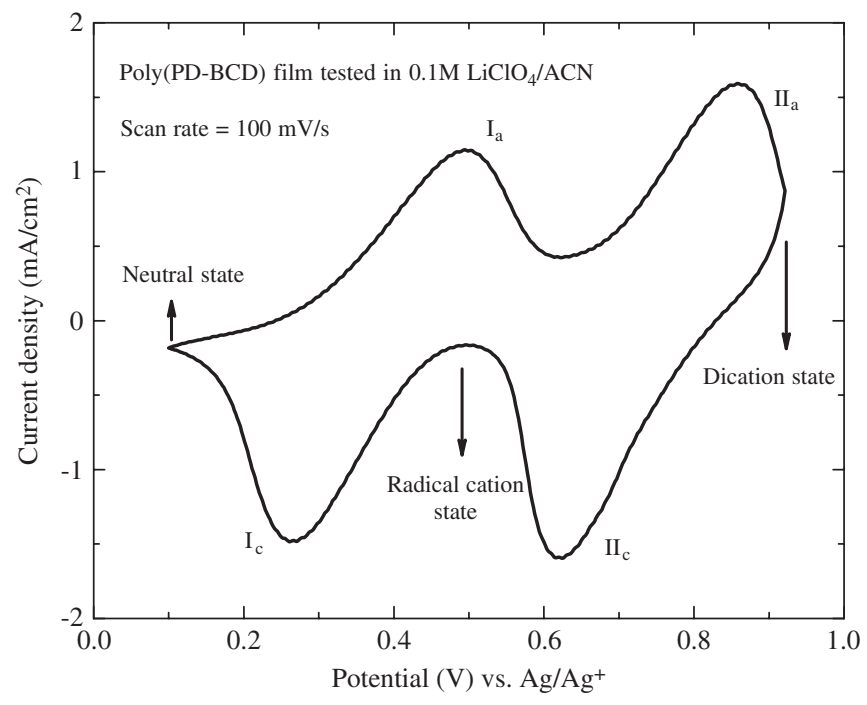

Fig. 2. The typical $\mathrm{CV}$ of poly(PD-BCD) $\left(C_{\text {dep }}=0.3 \mathrm{wt} \%\right)$ cycled in $0.1 \mathrm{M} \mathrm{LiClO}_{4} / \mathrm{ACN}$ solution with a scan rate of $100 \mathrm{mV} / \mathrm{s}$. The area of the film electrode is $2 \times 2 \mathrm{~cm}^{2}$.

redox reaction upon the applied potentials from 0.10 to $0.90 \mathrm{~V}$ and the results were presented in Fig. 2. The first redox reaction showed an oxidation peak $\left(\mathrm{I}_{\mathrm{a}}\right)$ at $0.49 \mathrm{~V}$ and a reduction peak $\left(\mathrm{I}_{\mathrm{c}}\right)$ at $0.27 \mathrm{~V}$, with a middle potential of about $0.38 \mathrm{~V}$ and the polymer film would change from the neutral state to the radical cation state. By increasing the applied potentials further from 0.50 to $0.90 \mathrm{~V}$, the second redox reaction showed an oxidation peak $\left(\mathrm{II}_{\mathrm{a}}\right)$ at $0.86 \mathrm{~V}$ and a reduction peak $\left(\mathrm{II}_{\mathrm{c}}\right)$ at $0.63 \mathrm{~V}$, with a middle potential of about $0.75 \mathrm{~V}$. Meanwhile, the film changed from the radical state to the dication state.

In order to understand the redox reaction mechanisms of poly(PD-BCD) films, the doping and de-doping processes of both reaction stages have been studied by an EQCM and by synchronous cyclic voltammetric $(\mathrm{CV})$ analysis.

Since the electroneutrality condition should be maintained, the amount of charge should be equal to the sum of electroactive species included in the electrolyte solution, and this could be expressed by the following equation $[1,21]$ :

$q=z_{\mathrm{A}}^{-} F \xi_{\mathrm{A}}^{-}-z_{\mathrm{C}}^{+} F \xi_{\mathrm{C}}^{+}$.

where $q$ is the amount of charge $(\mathrm{mC}), z_{\mathrm{A}}^{-}$and $z_{\mathrm{C}}^{+}$are the absolute values of the charge for anions and cations, $\xi_{\mathrm{A}}^{-}$ and $\xi_{\mathrm{C}}^{+}$are the numbers of mole of anions and cations. $F$ is the Faraday constant and the value is $96,485 \mathrm{C} / \mathrm{mol}$.

When the species (anions and/or solvent and/or cation) pass in and out of polymer matrix, the mass changes of poly(PD-BCD) films $(\Delta m)$ could be expressed by the following equation $[1,22]$ :

$\Delta m=M_{\mathrm{A}}^{-} \xi_{\mathrm{A}}^{-}+M_{\mathrm{C}}^{+} \xi_{\mathrm{C}}^{+}+M_{\mathrm{S}} \xi_{\mathrm{S}}$.

where $M_{\mathrm{A}}^{-}, M_{\mathrm{C}}^{+}$and $M_{\mathrm{S}}$ are the molar mass of anions, cations and solvent, $\xi_{\mathrm{S}}$ is the numbers of mole of solvent.

Before analyzing the CV-EQCM data obtained from these two redox reaction stages, the cationic effect has been confirmed first in order to simplify Eqs. (2) and (3). Using different perchlorate salts containing lithium $\left(\mathrm{Li}^{+}\right)$, sodium $\left(\mathrm{Na}^{+}\right)$and tetrabutylammonium $\left(\mathrm{TBA}^{+}\right)$as the supporting electrolytes, the mass changes per mole of electrons $(M)$ would become different if cations pass in and out of the polymer films during the voltammetric scan. Furthermore, " $M$ " could be expressed with the slopes of mass change $(\Delta m, \mathrm{ng})$ to the passed charge $(\Delta q, \mathrm{mC})$ after multiplying by some constants and could be calculated by

$M=10^{-6} \times \frac{\Delta m}{\Delta q} \times F$.

\subsubsection{The first redox reaction of poly $(P D-B C D)$}

Fig. 3 shows the plots of mass change vs. accumulated charge and the slopes of $\Delta m$ vs. $\Delta q$ were different when poly(PD-BCD) films were cycled separately in $\mathrm{LiClO}_{4}$, $\mathrm{NaClO}_{4}$ and $\mathrm{TBAClO}_{4}$. This shows that, in addition to the involvement of anions, cations also play some roles in the first redox stage. As a first approximation to simplify the problem, we neglect the solvent effect in the first redox stage of poly(PD-BCD) film and the redox mechanism could be proposed as below:

$$
\begin{aligned}
& \operatorname{poly}(\mathrm{PD}-\mathrm{BCD})+x \mathrm{Li}^{+}+(1+x) \mathrm{ClO}_{4}^{-}-\mathrm{e}^{-} \\
& \quad \leftrightarrow\left[\operatorname{poly}(\mathrm{PD}-\mathrm{BCD})^{+}: \mathrm{ClO}_{4}^{-}\right]\left(x \mathrm{LiClO}_{4}\right),
\end{aligned}
$$

where $x$ is the stoichiometric number of $\mathrm{Li}^{+}$.

Therefore, Eqs. (2) and (3) can be simplified further. The numbers of moles of anions and cations can be calculated by the following two equations [23]:

$$
\begin{aligned}
& \xi_{\mathrm{C}}^{+}=\frac{1}{\gamma} \Delta m-\frac{M_{\mathrm{A}}^{-}}{z_{\mathrm{A}}^{-} \gamma F} q, \\
& \xi_{\mathrm{A}}^{-}=\frac{z_{\mathrm{C}^{+}}}{z_{\mathrm{A}}^{-} \gamma} \Delta m+\frac{1}{z_{\mathrm{A}}^{-} F}\left(1-\frac{z_{\mathrm{C}^{+}} M_{\mathrm{A}^{-}}}{z_{\mathrm{A}}^{-} \gamma}\right) q,
\end{aligned}
$$

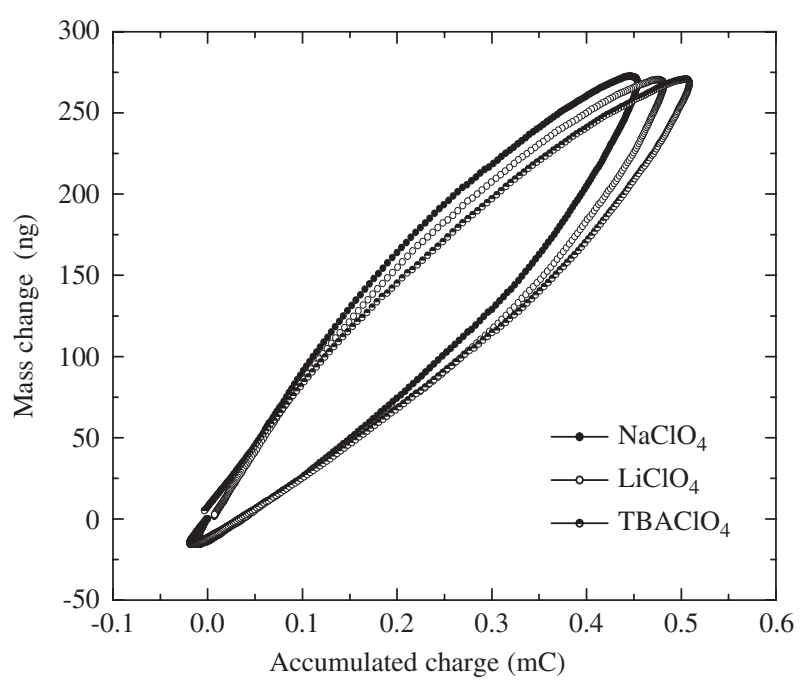

Fig. 3. The relationship between mass change and accumulated charge of poly(PD-BCD) films measured by $\mathrm{CV}$ cycling between 0.1 and $0.6 \mathrm{~V}$ in different electrolyte solutions containing $0.1 \mathrm{M} \mathrm{LiClO}_{4}, 0.1 \mathrm{M} \mathrm{NaClO}_{4}$ and $0.1 \mathrm{M} \mathrm{TBAClO}_{4}$, respectively. 
where $\gamma=\left(z_{\mathrm{A}}^{-} M_{\mathrm{C}}^{+}+z_{\mathrm{C}}^{+} M_{\mathrm{A}}^{-}\right) / z_{\mathrm{A}}^{-}, z_{\mathrm{A}}^{-}$and $z_{\mathrm{C}}^{+}$are equal to unity in this study. After further differentiation of Eqs. (6) and (7), both equations were transferred into Eqs. (8) and (9), thus the fluxes of anions and cations were obtained:

$\frac{\mathrm{d} \xi_{\mathrm{C}}^{+}}{\mathrm{d} t}=\frac{1}{M_{\mathrm{A}}^{-}+M_{\mathrm{C}}^{+}} \frac{\mathrm{d}(\Delta m)}{\mathrm{d} t}-\frac{M_{\mathrm{A}}^{-}}{\left(M_{\mathrm{A}}^{-}+M_{\mathrm{C}}^{+}\right) F} j$,

$\frac{\mathrm{d} \xi_{\mathrm{A}}^{-}}{\mathrm{d} t}=\frac{1}{M_{\mathrm{A}}^{-}+M_{\mathrm{C}}^{+}} \frac{\mathrm{d}(\Delta m)}{\mathrm{d} t}+\frac{M_{\mathrm{C}}^{+}}{\left(M_{\mathrm{A}}^{-}+M_{\mathrm{C}}^{+}\right) F} j$.

Fig. 4 shows the current density and the synchronous mass change of poly(PD-BCD) during the potentiodynamic cycles in the $0.1 \mathrm{M} \mathrm{LiClO}_{4} / \mathrm{ACN}$ electrolyte solution. Among which, the mass changes were divided into four stages ( $\mathrm{AB}, \mathrm{BC}, \mathrm{CD}$ and $\mathrm{DE})$. Therefore, a better understanding of the insertion and de-insertion conditions of the ions could be obtained at different potential windows.

From the CV-EQCM data shown in Fig. 4, one can obtain the molar fluxes of anions and cations, as calculated by Eqs. (8) and (9), and the results are depicted in Fig. 5. The positive molar flux indicated that ions would be inserted into the polymer matrix to compensate the charge. On the contrary, a negative molar flux means that ions would be extracted out of the film.

The variation of cationic fluxes was very small in the potential ranging from 0.10 to $0.25 \mathrm{~V}$ (which corresponds to A to B shown in Fig. 4). Here, anions $\left(\mathrm{ClO}_{4}^{-}\right)$were the predominant ions for charge compensation. In the same potential bias range, mass change of poly(PD-BCD) films decreased significantly due to $\mathrm{ClO}_{4}^{-}$moving out of the film, however the influence of cations on mass change was small. From 0.25 to $0.60 \mathrm{~V}$ (B to C), a large number of cations and anions would pass through the polymer matrix. This means that the charge compensation process would be achieved by the contributions from both cations and anions. In addition, the obvious mass variation from $\mathrm{B}$ to

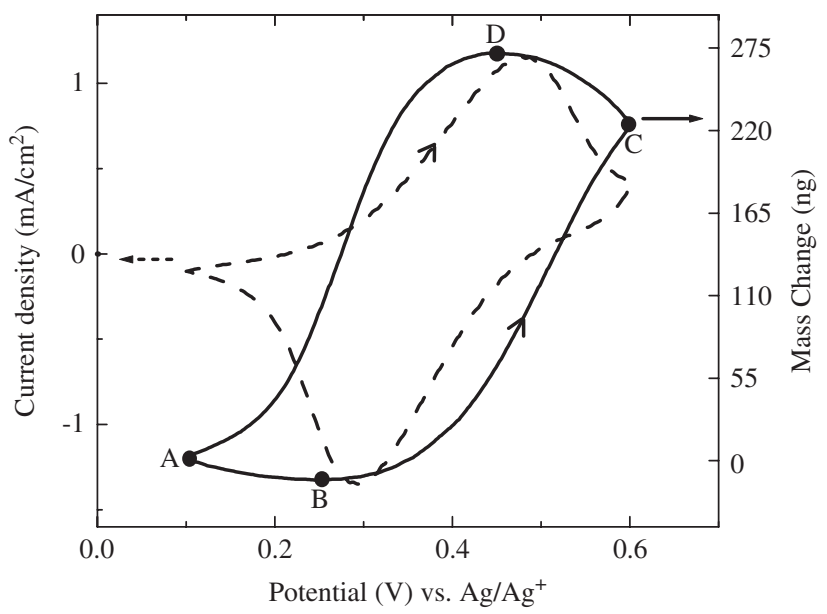

Fig. 4. The in situ CV-EQCM results of a poly(PD-BCD) film for 10 th cycle measured between 0.1 and $0.6 \mathrm{~V}$ in $0.1 \mathrm{M} \mathrm{LiClO}_{4} / \mathrm{ACN}$ with a scan rate of $100 \mathrm{mV} / \mathrm{s}$. Solid line is the mass change and dashed line is the current density of the poly(PD-BCD) film as a function of the potential.

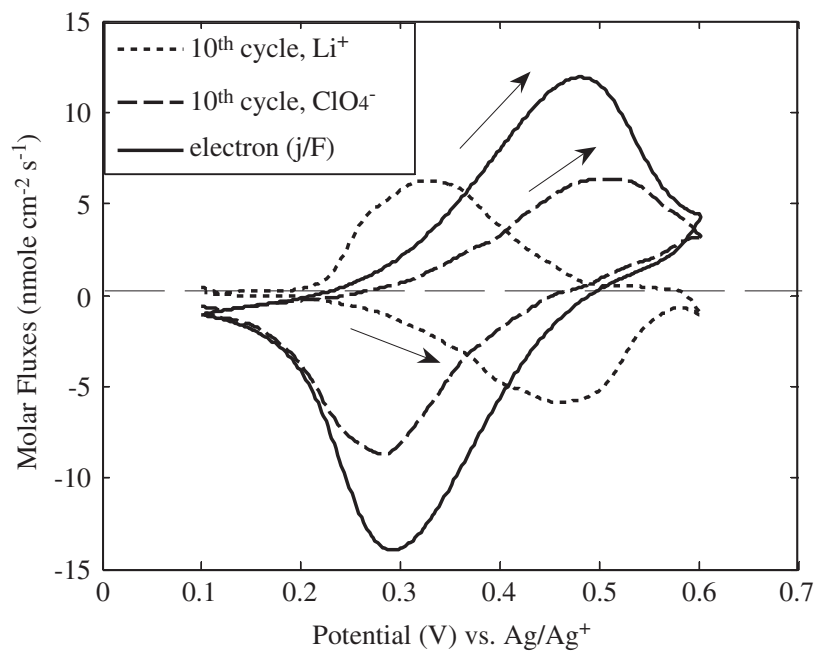

Fig. 5. The molar fluxes of cation $\left(\mathrm{Li}^{+}\right)$, anion $\left(\mathrm{ClO}_{4}^{-}\right)$and electron during the redox $\mathrm{CV}$ cycling of poly $(\mathrm{PD}-\mathrm{BCD})$ film between 0.1 and $0.6 \mathrm{~V}$.

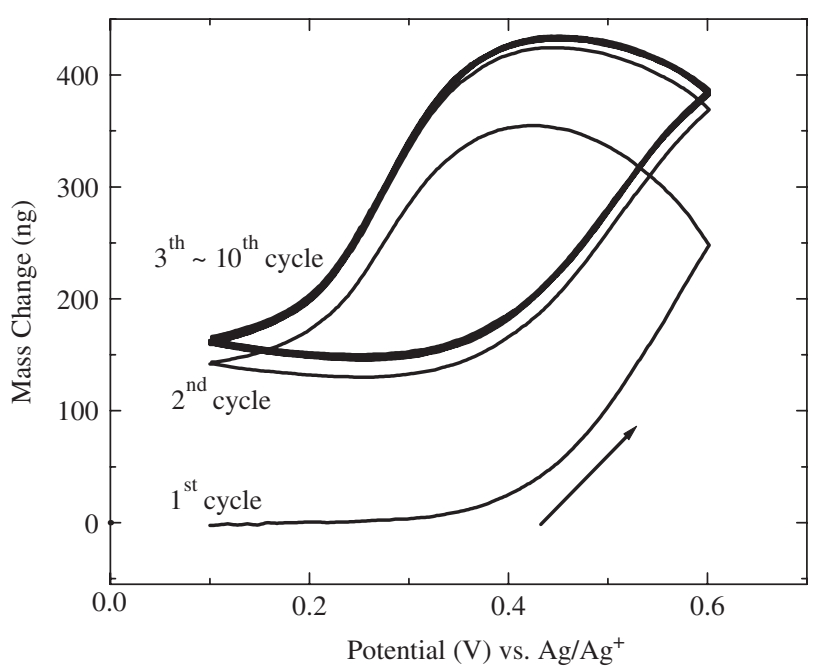

Fig. 6. The in situ mass change of poly(PD-BCD) film cycled in $0.1 \mathrm{M}$ $\mathrm{LiClO}_{4} / \mathrm{ACN}$ solution during $\mathrm{CV}$ cycling from 0.1 to $0.6 \mathrm{~V}$ for the first 10 cycles with a scan rate of $100 \mathrm{mV} / \mathrm{s}$.

$\mathrm{C}$ was caused by $\mathrm{ClO}_{4}^{-}$, since the molar mass of $\mathrm{ClO}_{4}^{-}$was about $99.45 \mathrm{~g} / \mathrm{mol}$, which is much higher than that of $\mathrm{Li}^{+}$, $6.94 \mathrm{~g} / \mathrm{mol}$. During the reductive process from 0.60 to $0.45 \mathrm{~V}$ (C to D), the mass change of the film would increase slightly since both ions were inserted into the polymer matrix. Further to decrease the bias from 0.45 to $0.10 \mathrm{~V}$ (D to A), a lot of cations would be inserted into the film, simultaneously anions would be extracted out of the film to neutralize the charge. As mentioned before $\left(\mathrm{ClO}_{4}^{-}\right.$showed a higher molar mass than that of $\mathrm{Li}^{+}$), anions still play the predominant role for the mass change of the films. Thus, in the range from $\mathrm{D}$ to $\mathrm{A}$, extraction of $\mathrm{ClO}_{4}^{-}$would cause the decrease of mass observed.

Fig. 6 shows the in situ mass change of poly(PD-BCD) film during $\mathrm{CV}$ cycling from 0.10 to $0.6 \mathrm{~V}$ for the first 10 cycles with a scan rate of $100 \mathrm{mV} / \mathrm{s}$. Except for the first cycle, all of the other cycles showed reasonably good 
reversibility, since the trajectories of $\Delta m$ vs. $E$ curves were almost the same. In the first cycle, obvious mass alteration was observed. This is because the polymer solution forming a poly(PD-BCD) thin film does not contain electrolyte. When a film electrode begins to oxidize, a lot of $\mathrm{ClO}_{4}^{-}$ would get inserted into the polymer film to neutralize the charge and this would make an apparent mass variation.

Since the cations would also participate in the first redox reaction of poly(PD-BCD) film, the accumulation of $\mathrm{LiClO}_{4}$ persists upon continuous cyclings. Eqs. (10) and (11), derived from Eq. (5), show the reaction mechanisms, respectively, for the oxidative and reductive processes of poly(PD-BCD) films:

$$
\begin{aligned}
& \operatorname{poly}(\mathrm{PD}-\mathrm{BCD})+\Delta x_{1} \mathrm{Li}^{+}+\left(1+\Delta x_{1}\right) \mathrm{ClO}_{4}^{-}-\mathrm{e}^{-} \\
& \quad \rightarrow\left[\text { poly }(\mathrm{PD}-\mathrm{BCD})^{+}: \mathrm{ClO}_{4}^{-}\right]\left(\Delta x_{1} \mathrm{LiClO}_{4}\right)
\end{aligned}
$$

$$
\begin{aligned}
& {\left[\operatorname{poly}(\mathrm{PD}-\mathrm{BCD})^{+}: \mathrm{ClO}_{4}^{-}\right]\left(\Delta x_{1} \mathrm{LiClO}_{4}\right)} \\
& +\Delta x_{2} \mathrm{Li}^{+}+\left(\Delta x_{2}-1\right) \mathrm{ClO}_{4}^{-}+\mathrm{e}^{-} \\
& \quad \rightarrow \operatorname{poly}(\mathrm{PD}-\mathrm{BCD})]\left(\Delta x_{1}+\Delta x_{2}\right)\left(\mathrm{LiClO}_{4}\right)
\end{aligned}
$$

After an oxidative process, one gets the stoichiometric number of $\mathrm{LiClO}_{4}$ equal to $\Delta x_{1}$, and after a further reductive process, the accumulated stoichiometric number of $\mathrm{LiClO}_{4}$ would become $\Delta x_{1}+\Delta x_{2}$. The accumulated phenomenon would come into existence if $\Delta x_{1}+\Delta x_{2}$ represents a value higher than zero. By comparing the stoichiometric number between lithium and electron, $\Delta x_{1}$ and $\Delta x_{2}$ can be calculated by Eqs. (12) and (13). The stoichiometric numbers are shown as absolute values in the following equations:

$$
\begin{aligned}
& \frac{\mathrm{Li}^{+}}{\mathrm{e}^{-}}=\frac{\Delta x_{1}}{|-1|}=\frac{\xi_{\mathrm{C}^{+}}^{\mathrm{O}}-\xi_{\mathrm{C}^{+}}^{\mathrm{R}}}{\left|\left(Q_{\mathrm{O}}-Q_{\mathrm{R}}\right) / F\right|}, \\
& \frac{\mathrm{Li}^{+}}{\mathrm{e}^{-}}=\frac{\Delta x_{2}}{|1|}=\frac{\xi_{\mathrm{C}^{+}}^{\mathrm{R}}-\Delta \xi_{\mathrm{C}^{+}}^{\mathrm{O}}}{\left|\left(Q_{\mathrm{R}}-Q_{\mathrm{O}}\right) / F\right|},
\end{aligned}
$$

where $\Delta x_{1}$ and $\Delta x_{2}$ are the stoichiometric numbers of lithium that are shown in Eqs. (10) and (11). According to Eq. (6), the variation of cationic moles between an oxidative state $\left(\xi_{\mathrm{C}^{+}}^{\mathrm{O}}\right)$ and a reductive state $\left(\xi_{\mathrm{C}^{+}}^{\mathrm{R}}\right)$ could be obtained. Moreover, under the same condition, the corresponding charges of oxidation and reduction, represented by as $Q_{\mathrm{O}}$ and $Q_{\mathrm{R}}$, respectively, can also be calculated. The results of accumulation of $\mathrm{Li}^{+}$at various cycles have been summarized in Table 1 .

Table 1

A summary of the stoichometric number of $\mathrm{Li}^{+}$calculated from oxidative and reductive processes of the first redox reaction region $(0.1-0.6 \mathrm{~V})$ of poly(PD-BCD) at 5th, 10th and 20th cycles

\begin{tabular}{lrrrr}
\hline & \multicolumn{1}{l}{ 1st } & \multicolumn{1}{l}{ 2nd } & \multicolumn{1}{l}{ th } & \multicolumn{1}{l}{10 th } \\
\hline Oxidative process $\left(\Delta x_{1}\right.$, moles $)$ & -0.370 & -0.466 & -0.486 & -0.486 \\
Reductive process $\left(\Delta x_{2}\right.$, moles $)$ & 0.670 & 0.491 & 0.479 & 0.479 \\
Accumulation $\left(\Delta x_{1}+\Delta x_{2}\right.$, moles $)$ & 0.300 & 0.025 & -0.007 & -0.007 \\
\hline
\end{tabular}

When a poly(PD-BCD) film begins to oxidize, lots of anions should be inserted into the film to compensate charge and the electrical attraction of anions may cause cations to move into the polymer matrix and further make a large accumulation of $\mathrm{LiClO}_{4}$. In the second cycle, probably a better communication between the electrode and ions was reached and this was responsible for the less accumulation of ions.

After five cycles, the accumulation showed a stoichiometric value $\left(\Delta x_{1}+\Delta x_{2}\right)$ smaller than zero and the reason is that the $\mathrm{LiClO}_{4}$ accumulated during the previous cycles would be expelled when a better communication between the electrode and ions was attained through cyclings.

\subsubsection{The second redox reaction of poly $(P D-B C D)$}

For the second redox stage, cationic effects have also been confirmed by three electrolytes, $\mathrm{LiClO}_{4}, \mathrm{NaClO}_{4}$ and $\mathrm{TBAClO}_{4}$. Fig. 7 showed the relationship between mass change and accumulated charge of poly(PD-BCD) films measured by $\mathrm{CV}$ cycling between 0.50 and $0.90 \mathrm{~V}$ in these three electrolyte solutions. The slopes of $\Delta m$ vs. $Q$ obtained from the CV-EQCM data were almost the same for these supporting electrolytes. This shows that cations play significantly less role in the second reaction stage and as a result of this, the representative species toward mass change would become anions and solvent. In addition, the equations of mass transition and charge conservation can be rewritten by the following equations:

$Q=z_{\mathrm{A}^{-}} F \xi_{\mathrm{A}^{-}}$,

$\Delta m=W_{\mathrm{A}^{-}} \xi_{\mathrm{A}^{-}}+W_{\mathrm{S}} \xi_{\mathrm{S}}$.

Moreover, the molar fluxes of both anions and solvent can be calculated by

$\frac{\mathrm{d}}{\mathrm{d} t}\left(\frac{M_{\mathrm{S}} \xi_{\mathrm{S}}}{M_{\mathrm{A}}^{-}}\right)=\frac{1}{M_{\mathrm{A}}^{-}} \frac{\mathrm{d}(\Delta m)}{\mathrm{d} t}-\frac{j}{F}$,

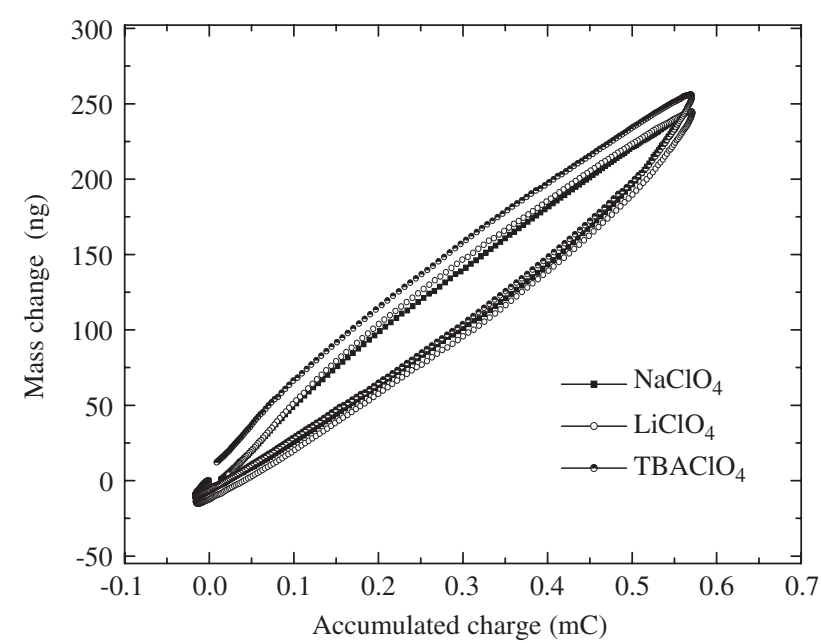

Fig. 7. The relationship between mass change and accumulated charge of poly(PD-BCD) films measured by $\mathrm{CV}$ cycling between 0.5 and $0.9 \mathrm{~V}$ in different electrolyte solutions containing $0.1 \mathrm{M} \mathrm{LiClO}_{4}, 0.1 \mathrm{M} \mathrm{NaClO}_{4}$ and $0.1 \mathrm{M} \mathrm{TBAClO}_{4}$, respectively. 
$\frac{\mathrm{d}}{\mathrm{d} t}\left(\xi_{\mathrm{A}}^{-}+\frac{M_{\mathrm{S}} \xi_{\mathrm{S}}}{M_{\mathrm{A}}^{-}}\right)=\frac{1}{M_{\mathrm{A}}^{-}} \frac{\mathrm{d}(\Delta m)}{\mathrm{d} t}+\frac{j}{M_{\mathrm{A}}^{-} F}$.

And the reaction mechanism for the second reaction stage is proposed as follows:

$$
\begin{aligned}
& {\left[\text { poly }(\mathrm{PD}-\mathrm{BCD})^{+} \mathrm{ClO}_{4}^{-}\right]+\mathrm{ClO}_{4}^{-}} \\
& \quad \leftrightarrow\left[\text { poly }(\mathrm{PD}-\mathrm{BCD})^{+2}\left(\mathrm{ClO}_{4}^{-}\right)_{2}\right]+\mathrm{e}^{-} .
\end{aligned}
$$

A plot of current density and mass change vs. potential is shown in Fig. 8, and some symbols $\left(\mathrm{A}^{\prime}, \mathrm{B}^{\prime}, \mathrm{C}^{\prime}\right.$ and $\left.\mathrm{D}^{\prime}\right)$ have also been used to divide the mass change of the second redox reaction into four regions. To provide more clarify with regard to the insertion and extraction condition of anions and solvent during these potential windows that are demarcated by $\mathrm{A}^{\prime}, \mathrm{B}^{\prime}, \mathrm{C}^{\prime}$ and $\mathrm{D}^{\prime}$ and a flux plot of both species is depicted in Fig. 9.

During the oxidative process from $0.50 \mathrm{~V}\left(\mathrm{~A}^{\prime}\right)$ to $0.63 \mathrm{~V}$ $\left(\mathrm{B}^{\prime}\right)$, the anions would move out of the film first and after the bias was further increased to $0.90 \mathrm{~V}\left(\mathrm{C}^{\prime}\right)$, the anions

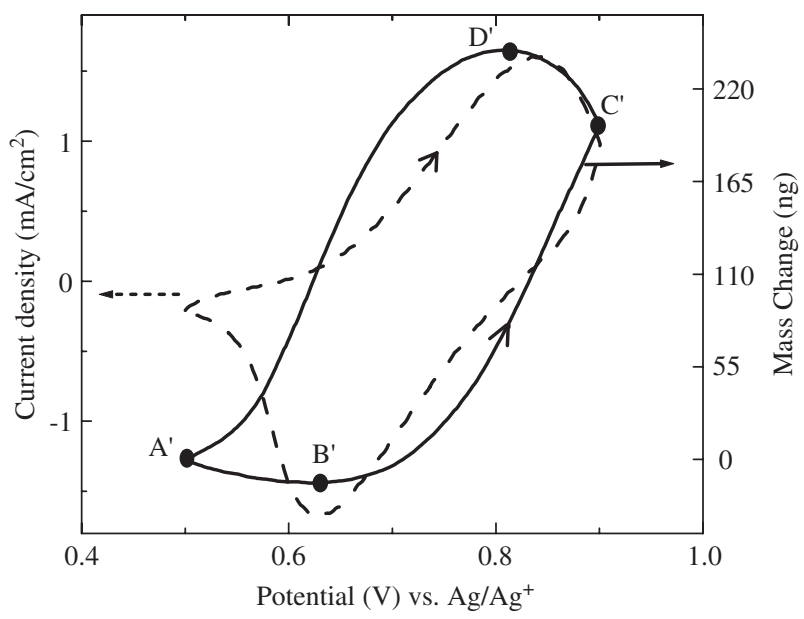

Fig. 8. The in situ CV-EQCM result of poly(PD-BCD) film cycled between 0.5 and $0.9 \mathrm{~V}$ in $0.1 \mathrm{M} \mathrm{LiClO}_{4} / \mathrm{ACN}$ with a scan rate of $100 \mathrm{mV} / \mathrm{s}$.

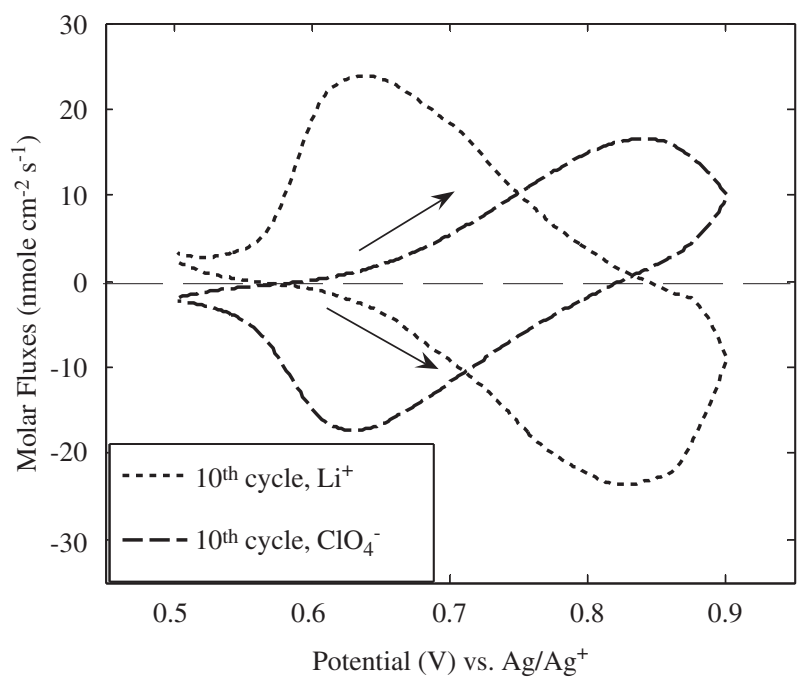

Fig. 9. The molar fluxes of cation $\left(\mathrm{Li}^{+}\right)$, anion $\left(\mathrm{ClO}_{4}^{-}\right)$and electron during the redox cycling of poly(PD-BCD) film from 0.5 to $0.9 \mathrm{~V}$.
Table 2

A summary of the solvent to anion flux ratio calculated from the oxidative process $\left(\alpha^{\mathrm{O}}\right)$ for the 10th cycle of poly(PD-BCD) at different applied potentials

\begin{tabular}{lccccc}
\hline Oxidative process (V) & 0.5 & 0.6 & 0.7 & 0.8 & 0.9 \\
$\alpha^{\mathrm{O}}$ & 1.2 & -4.03 & -1.68 & -1.49 & -0.87 \\
\hline
\end{tabular}

Table 3

A summary of the solvent to anion flux ratio calculated from the reductive process $\left(\alpha^{\mathrm{R}}\right)$ for the 10 th cycle of poly(PD-BCD) at different applied potentials

\begin{tabular}{lcllll}
\hline Reductive process $(\mathrm{V})$ & 0.9 & 0.8 & 0.7 & 0.6 & 0.5 \\
$\alpha^{\mathrm{R}}$ & -0.87 & 1.95 & 1.55 & 1.24 & 1.41 \\
\hline
\end{tabular}

would move into the film electrode. Simultaneously, solvent proceeded the opposite way to anions under the same applied voltages.

During the reductive process, from $0.90 \mathrm{~V}\left(\mathrm{C}^{\prime}\right)$ to $0.82 \mathrm{~V}$ $\left(\mathrm{D}^{\prime}\right)$ and further to $0.50 \mathrm{~V}\left(\mathrm{~A}^{\prime}\right)$, anions would be inserted into the film first and then a large number of anions would be extracted out of the film, whereas solvent would show the opposite way to anions at the same voltages.

Anions are the only charged species that one is concerned within the second redox reaction stage and hence, anions are the representative species during the charge compensation process. In addition, if we observe the mass change from EQCM data that have been depicted in Fig. 8, we can see that anions dominate over the mass transition of films even though the solvent shows higher flux variation at most applied voltages. This is because anions possess higher molar mass than that of solvent (containing $41 \mathrm{~g} / \mathrm{mol}$ ).

Tables 2 and 3 show solvent to anion flux ratio $(\alpha)$ which was calculated, respectively, from the oxidative and reductive processes for the 10th cycle of poly(PD-BCD). Here, we allow anion to take an absolute flux value thus we can easily ascertain the transfer direction for solvent.

In the oxidative process at $0.60 \mathrm{~V}$, there appeared a large value of $\alpha^{\mathrm{O}}$ when anions were inserted into the poly(PD$\mathrm{BCD}$ ) film, and the reason is that denominator (anionic fluxes) shows a value approaching zero. Therefore, this will cause a higher value of $\alpha^{\mathrm{O}}$. Similarly, a large $\alpha^{\mathrm{R}}$ value shows up at $0.8 \mathrm{~V}$ during the reductive process and is also due to the near zero value of anionic fluxes.

\section{Conclusions}

A new aromatic poly(amine-imide) electrochromic thin film synthesized with $N, N$-bis-(4-aminophenyl)- $N^{\prime}, N^{\prime}$-diphenyl-1,4-phenylenediamine and 3,3',4,4'-benzo-phenonetetra carboxylic dianhydride, abbreviated as poly(PD$\mathrm{BCD}$ ), have been investigated in this study. There are two redox reaction stages that appear during the electrochemical reaction. Since the polymer chain possesses positive charge when poly(PD-BCD) was oxidized to its 
radical cation state or dication state, the anions would insert into the polymer matrix in order to neutralize the charge. However, when the electrodes were cycled in electrolytes containing different perchlorate salts, such as $\mathrm{LiClO}_{4}, \mathrm{NaClO}_{4}$ and $\mathrm{TBAClO}_{4}$, the plots of mass change $(\Delta m)$ vs. accumulated charge $(Q)$ gave different slopes in the first reaction stage but in the second reaction stage the slopes were almost the same. This implies that, in addition to the involvement of anions, cations also play an important role in the first redox stage, but cations play significantly less role in the second stage. Using the $\mathrm{CV}-\mathrm{EQCM}$ technique, plausible mechanisms regarding these two redox reaction are proposed.

\section{Acknowledgments}

The authors wish to thank Ritdisplay Corporation, Hsinchu Industrial Park, Taiwan, for providing the conductive ITO glass substrates. The financial support provided by the National Science Council of Taiwan, R.O.C., is appreciated.

\section{References}

[1] F. Blanchard, B. Carré, F. Bonhomme, P. Biensan, H. Pagés, D. Lemordant, J. Electroanal. Chem. 569 (2004) 203.

[2] D.B. Wurm, Y.-T. Kim, Langmuir 16 (2000) 4533.
[3] I. Efimov, S. Winkel, J.W. Schultze, J. Electroanal. Chem. 499 (2001) 169.

[4] W. Paik, I.-H. Yeo, H. Suh, Y. Kim, E. Song, Electrochim. Acta 45 (2000) 3833.

[5] G. Inzelt, Electrochim. Acta 45 (2000) 3865.

[6] A. Bund, S. Neudeck, J. Phys. Chem. B 108 (2004) 17845.

[7] N. Li, K. Carita, I. Ari, J. Electroanal. Chem. 569 (2004) 151.

[8] B. Wang, J. Zhang, G. Cheng, S. Dong, Anal. Chim. Acta 407 (2000) 111.

[9] J.D. Craig, R.D. O’Neill, Analyst 128 (2003) 905.

[10] K.A. Marx, T. Zhou, J. Electroanal. Chem. 501 (2001) 107.

[11] T. Ohtsuka, T. Wakabayashi, H. Einaga, J. Electroanal. Chem. 377 (1994) 107.

[12] A.R. Hillman, M.J. Swann, S. Bruckenstein, J. Phys. Chem. 95 (1991) 3271.

[13] L. Niu, C. Kvarnström, S. Dong, A. Ivaska, Synth. Met. 121 (2001) 1389.

[14] E.J. Calvo, A. Wolosiuk, J. Am. Chem. Soc. 124 (2002) 8490.

[15] E.J. Calvo, E.S. Forzani, M. Otero, Anal. Chem. 74 (2002) 3281.

[16] T. Frelink, W. Visscher, J.A.R. van Veen, Langmuir 12 (1996) 3702.

[17] E.W. Bohannan, L.-Y. Huang, F.S. Miller, M.G. Shumsky, J.A. Switzer, Langmuir 15 (1999) 813.

[18] T.D. Selby, K.-Y. Kim, S.C. Blackstock, Chem. Mater. 14 (2002) 1685.

[19] S.-H. Cheng, S.-H. Hsiao, T.-H. Su, G.-S. Liou, Macromolecules 38 (2005) 307.

[20] G. Sauerbrey, Z. Phys. 155 (1959) 206.

[21] D.A. Buttry, M.D. Ward, Chem. Rev. 92 (1992) 1355.

[22] S.L. de Albuquerque Maranhão, R.M. Torresi, J. Electrochem. Soc. 146 (1999) 4179.

[23] H. Varela, R.L. Bruno, R.M. Torresi, Polymer 44 (2003) 5369. 